\section{Faculty start-ups offer temptation to breach academic rules ...}

Sir-There is a growing discomfort in the academic community about our financial and structural relations with the corporate sector, as identified in your timely Opinion article "Is the university-industrial complex out of control?" (Nature 409, 119; 2001). But I believe the situation is much more complex than you have described, and the "new year's resolutions" you offer as solutions are rather misdirected.

You describe benefits to researchers and universities, but these relate only to collaborations with large corporations, not smaller companies or faculty start-ups. In my 20-year experience, collaborations and/or contract research agreements with large companies are typically straightforward and non-controversial. Ownership issues are contractually spelt out: the university retains ownership, with various licensing rights accruing to the company. The technologies covered are specified with mutual consent. Publication delays (if requested) are specified within university policy — short delays are generally allowed to protect intellectual property rights.

There are examples that deviate from this norm. But universities do not have to make agreements that do not meet normal academic criteria. They should refuse relationships that might, for example, restrict academic freedom or improperly institutionalize a company's influence.

What institutions need is good advice on how to forge a reasonable collaboration, and protection from its faculty members, who may be clamouring to accept finance for their research at any price. Both problems would be reduced by a manifesto in which universities would adhere to a common corporate contract, with exceptions possible and noted when necessary. Some inappropriate deals are signed because universities believe that if they don't, some other university will.

Your editorial suggests that academics should "stand up for themselves, with the protection of university constitutions and hierarchies". But academics are not a single entity. Corporate-university interactions are irrelevant to many, who have opposed partnerships with industry.

There are very significant differences in the relationships a company wants with an institution: commercial exploitation of some technologies depends on know-how and speed of market penetration, whereas in others it depends on a solid base of intellectual property protection. It is not clear to me what faculty members would say if they were to attempt to speak with a single voice, other than insist on academic freedom. While laudable, that is not enough.

Where I believe university-industry relations are truly "out of control" is in our dealings with small companies, especially those founded on the basis of discoveries by faculty members where the individual and the institution both hold equity.

The benefits of corporate partnership do not typically flow from deals with small companies. These, especially faculty startups, rarely have valuable databases, unique facilities, market access or any assets other than the technology available through a university licence. The driving principle is not to benefit university research, but to benefit the faculty member financially. Conflicts of interest in these cases are most difficult for the university to administer.

Although virtually every university has policies to define acceptable behaviour, policies alone are not sufficient. Biased publications and undeclared conflict of interest are inappropriate actions by individual academics. And what about undeclared consulting benefits, undetected data manipulation, unregistered transfer of university intellectual property, undeclared equity interest, inappropriate use of federally supported students and postdocs on company projects, and so on?

The only "resolution" that will solve these problems is for universities to ban their academic staff from simultaneously holding equity in a company, and to severely discipline those who make corporate relationships on their own.

I am convinced that, done properly, academic-corporate collaborations benefit both partners, enhance the quality of university research and are in the public good. It is expecting too much to suppose that academics and their institutions can always act prudently and responsibly when each holds equity in the same venture. Universities should take equity because that is how they recoup the public's investment in their research. Faculty members cannot realistically be expected to invest simultaneously in the public good and their own private financial interests. Richard K. Koehn

Department of Biology, University of Utah, Salt Lake City, Utah 84112, USA

\section{... but Syngenta deal is a boon to Berkeley}

Sir- The editorial "Is the universityindustrial complex out of control?" (Nature 409, 119; 2001) stated that Novartis (now Syngenta) "gains a seat in university and departmental research committees and restricts academics' freedom to discuss the benefits of the deal".
As graduate students of Berkeley's plant and microbial biology department, which has made the collaborative agreement with Syngenta, we disagree. We are free to discuss the benefits of the deal, and department committees at Berkeley do not contain members from the company. There is, however, one new committee dedicated solely to awarding research funds from Syngenta, which does include company representatives.

Ironically, Berkeley was the lead player in your Opinion article, but the agreement between Berkeley and Novartis in 1998 is a model for the "new year's resolutions" that the article listed. Information about the agreement is available at plantbio.berkeley. edu/PMB-TMRI, including limits to publication delay, restrictions on licensing, and a list of projects funded. This document illustrates that the basic research mission of the department is promoted by the collaboration.

Matthew Metz

Department of Plant and Microbial Biology, 11 Koshland Hall, University of California, Berkeley, California 94720, USA

Other signatories to this letter:

J. Peter Coppinger, Carolyn Rasmussen, Jinjer Larsen, Michael J. Axtell, Rebecca Middleton, Meredith Johnson, Jennifer Bragg, Jennifer Johnson

\section{'Art' was a load of fluff}

Sir - The word 'bollocks' appeared in Nature for the first time (Nature 392, 663; 1998) when Martin Kemp quoted the reaction of a lowly Leicester University student to some photographs published in Kemp's 'Art and Science' series.

I was that student, and the remark ended up in Kemp's article because, on seeing Cornelia Parker's photographs of navel fluff and the like, I had exclaimed "What's this bollocks doing in Nature?" to his daughter Dr Joanna Kemp, who was also at Leicester at the time. Unfortunately, I was at sea when the second article was published, so was unable to respond to his somewhat scathing comments.

As it is sadly likely that my association with Kemp's article is the closest that I will ever get to a Nature publication, I am grateful for this opportunity to have my contribution to advancing the understanding between science and art formally acknowledged by your publication of this letter.

The fact that I am responsible for the word 'bollocks' first appearing in Nature is not only a brilliant addition to my CV but may even represent the pinnacle of my scientific career.

Magnus Johnson

Scarborough Centre for Coastal Studies, University of Hull, Filey Road, Scarborough YO11 3AZ, UK 